
nacida en 1935. Es preferentemente narradora y dramaturga. Su producción narrativa es numerosa pero hasta la fecha ha editado seis colecciones de cuentos, $L a$ oscuridad de afuera (1987), Entre ánimas y sueños (1987), Demasiada historia (1988), Efectos especiales (1989), Preludio con fuga (1992) y Presentes anteriores (1996). En novela, es autora de Los fantasmas no son como antes, Juicio a la memoria y Desde cierta distancia, pero sólo ha publicado Nocturno para errantes eternos (1999), Premio Gabriel Casaccia. Como teórica, participa con regularidad en los congresos de LASA.

\title{
EL PUNTILLISMO NARRATIVO EN LA OBRA DE GABRIEL CASACCIA
}

\author{
SARA KARLIK
}

Alguien lo llamó «el novelista del pueblo», tal vez por esa característica suya de adentrarse en la piel de los personajes, sobre todo de sus novelas, y explotar en ellos el sentido de la tierra, hasta que la muerte se lleva sus últimas ilusiones.

Casaccia nace en 1907 y emigra a la Argentina en 1935, después de la Guerra del Chaco. En 1963, le otorgan el premio Kraft en Buenos Aires por su novela La llaga. En 1966 obtiene el premio Primera Plana Editorial Sudamericana por su novela Los exiliados, mientras que Los herederos y Los Huertas fueron finalistas en otros concursos.

Casaccia ubica sus historias en Areguá, pueblo ubicado a $30 \mathrm{kms}$ de Asunción, en el silencio de sus más de 400 años de historia. Sus propias amarguras y esperanzas le hacen apelar a seres aparentemente rescatados de la mitología local. Descarnado en la percepción de sus compatriotas, no escatima esfuerzos para pintarlos como en verdad son en el proceso que inicia su caída y el terrible esfuerzo infructuoso por levantarse. La realidad es para el autor su lente identificadora.

La mayor parte de sus personajes está determinada por una fatalidad que parece acompañar todas sus narraciones. "Novelista de la degradación», lo denomina Rubén Bareiro, sobre todo al referirse a la atmósfera infernal de Areguá que tanto víctimas como victimarios ayudan a crear. Sólo en Los exiliados el escenario cambia, por necesidad de lo que se narra y de lo que experimentan sus personajes al adquirir la categoría de expatriados, sin por eso cambiar el tono intimista de la narración. El autor no escatima detalle o alcance acertivo para delinear lo que podría denominarse como puntillismo narrativo, el factor que mueve el interior de sus personajes con la intensidad de sus descripciones, pintándolos con colores que destacan y los identifican hasta crear los tipos necesarios para que produzcan en el lector la total identificación de ellos, alimentando la fantasía del lector e incorporándolo al mismo tiempo como personaje clave Consigue así el autor, que la imagen, la letra y los significados se fundan. Su realidad se vuelve la del lector.

Hombres, mujeres y fantoches (1929), única novela publicada en el Paraguay a los 22 años, así como El bandolero (1932), única pieza teatral, fueron criticadas por su lenguaje afectado y la poca profundización que hace de los personajes, y tildada como obra primeriza de un autor novel en el oficio. Es la presentación novelada de hombres y mujeres con inclinaciones $\mathrm{y}$ aprensiones corrientes, $\mathrm{y}$ de los fantoches, políticos corruptos que ilustran el período.

La lucha entre el bien y el mal en una atmósfera de tintes bíblicos ilustra el desarrollo de El bandolero, donde la cuestión religiosa y los símbolos adquieren ribetes de necesidad imprescindible en los ocho retablos de que se compone la obra. La atmósfera bíblica contrapone las figuras míticas de Caín y Abel.

Mario Pareda (1940) es una nowvelle en la que Casaccia cifró esperanzas, pero que resulta algo así como una obra frustrada, pues su protagonista siempre le persigue, viendo en él algo del Atilio de La Llaga. Es la búsqueda de sí mismo lo que insufla aire a Mario Pareda, 
haciendo eco de los problemas que lo atormentan, basado en un supuesto manuscrito entregado al autor que da origen a una ficción manipulada. Con todas sus debilidades, fue considerada la entrada de la novela dentro del ámbito local.

La Babosa (1952) es quizás la novela que más lo identifica y que le ha dado el renombre de novelista naturalista. En medio del tedio aplastante, decadente, deshumanizante, el protagonista, Ramón Fleitas, arribista y joven abogado, pretende desprenderse de su origen campesino casándose con Adela, la hija de un connotado abogado asunceno. Obligado a vivir en Areguá ve reprimido su deseo de convertirse en poeta. Ángela es quien lleva y trae la trama a través de su condición de «babosa», como la denomina el padre Rosales, algo que nunca la mujer le pudo perdonar. Ángela es una necesidad para Areguá, una forma de aguantar el tedio. Los mensajes anónimos, que sólo tienen el nombre de tales pues son fácilmente identificables, constituyen otra forma de capear el aburrimiento y resistir la convivencia.

Todos los personajes tratan de sacar partido de su posición o son sometidos por los deseos de otros más astutos. El amor carnal es la única salida para la mediocridad del lugar, que a su vez incide en la mediocridad de la gente. Por la misma razón, se vuelve costumbre, y es así que llega a ser natural la sumisión de la campesina que sirve en la casa como sirvienta. Fleitas se maneja entre la envidia y la frustración y por lo mismo cae en deudas de juego, una de sus pasiones, falta de discernimiento, la amistad con Espinoza, personaje oscuro que maquinará al final, la forma de quedarse con las joyas de Clara.

Las circunstancias convierten a todos en culpables y pecadores, igualados por la fatalidad. La astucia se vuelve un juego existencial cotidiano y es la que ofrece mejores dividendos. El padre Rosales equilibra de algún modo situaciones que a menudo escapan a su discreción de religioso.

El falso testimonio y la mediocridad se convierten en gimnasia y disciplina de sobrevivencia. El tiempo pasa, sin que nadie repare en su paso. El deterioro de Ramón Fleitas aumenta. Derrumbado, vuelve a ser el hombre rastrero de siempre. La hostilidad entre las hermanas Gutiérrez no cesa hasta la muerte de Clara, a quien Ángela hostigó con el pretexto

de cuidarla luego del violento robo del que fuera objeto por Espinoza.

«No es el novelista el que ha ido a la realidad que lo circunda; es la vida lo que ha penetrado en el orbe del novelista», afirma Casaccia cuando critican su inclemente escritura. Esta realidad lo lleva a desnudar el espíritu de sus protagonistas sin importar si son condenados o salvados por esa realidad.

En La llaga (1964) el detalle no cae en el exceso como en sus otras obras, haciendo más fácil y rápida la lectura. Siempre anteponiendo como fondo el pueblo de Areguá, cuenta el

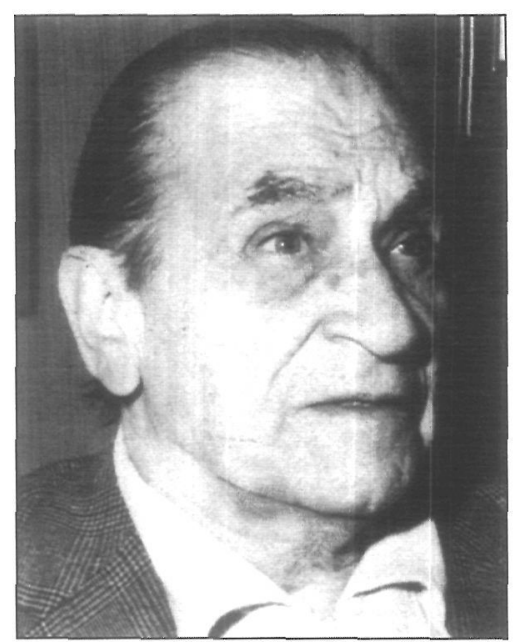

Gabriel Casaccia. autor la historia de Constancia y sus amores de viuda con Gilberto - mismos personajes que reaparecen en Los exiliados-, del temor de la mujer de envejecer, perdiendo su atractivo. Se apela a la intriga, lo oculto, la persecución, la denuncia en medio del desarraigo de la pasión amorosa o la exacerbación de ésta, el abandono, la supremacía del hombre como parte fuerte y decisiva en la relación de pareja. La cuestión política, el incesto amenazante, el conflicto madre-hijo, la soledad, la muerte, son los que mueven la trama.

La trama de Los exiliados (1966) transcurre en Posadas, Argentina, ciudad fronteriza separada por el río Paraná. Personajes como el abogado Rolando Gamarra, Etelvina su mujer, Leoni el hijo, Graciela la hija, se mueven dentro de la atmósfera del exilio y achacan sus problemas a las consecuencias de la situación en que se encuentran. Gamarra y Etelvina son propietarios del Hotel Guaraní.

Gilberto Torres, aparece como pintor; Ramón Fleitas, en La Babosa, es el símil de Gilberto Torres. Los exiliados viven pendientes de lo que ocurre en Asunción y la radio se convierte en un elemento aproximador. $\mathrm{La}$ conspiración deviene en obsesión de cambios. El mito del regreso, mantiene la ilusión.

El prostíbulo de Valentina - «la Polaca», como la conocen - es el refugio donde la pena busca consuelo. Dionisio - Leoni-, hijo de Gamarra, concubino de la Polaca, le robará sus joyas. Pasiones de toda índole se desencadenan en el burdel. No sólo el burdel prostituye, sino también el destierro, el alcohol corre como elemento emancipador del alma, del ocio. Algunos personajes de La Llaga, reaparecen, como Constancia y Gilberto que conti- 


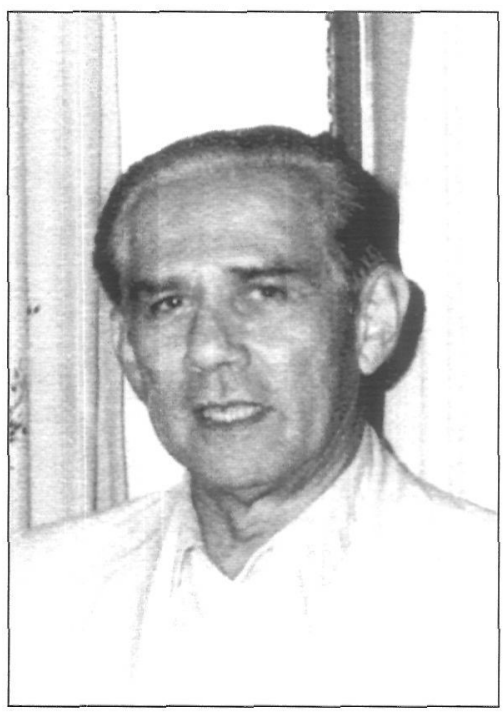

José Ma Rivarola Malto (Foto de Manuel Rivarola). núan su deambular amatorio entrecortado por las circunstancias. Los personajes son perezosos, aprovechadores, colgados del exilio que los identifica y da pie a conductas de autodefensa o autojustificación. La sensación final es de derrota colectiva del deseo doloroso del regreso.

Como señala Casaccia cuando pinta los caracteres y pasiones de Los exiliados, no resalta el heroísmo del exilio, sino la caída del hombre. Hugo Rodríguez Alcalá sostiene que en la obra de Casaccia abunda, no lo que más ama el autor, sino lo que más odia. Otros agregan que es cruel, desprejuiciado, pero sobre todo valiente. Josefina Plá dice de Los exiliados que es «un documento despiadado sobre ciertos aspectos de la psicología colectiva». Casaccia tuvo la visión de proyectar Areguá con su envoltura candente, convertida en lugar de vacaciones para la gente de Asunción, en la idiosincracia de los protagonistas, llevándolos a extremos para probar su resistencia. Areguá es, para Casaccia, el lugar de sus recuerdos, de su infancia, de la adolescencia enfermizamente despiadada.

En Los herederos (1975), el mismo escenario se mantiene: Areguá. Al decir de Francisco Feito, los protagonistas de Casaccia son personajes tipo. Se repiten en sus escritos para diseñar distintas historias. Con la caída del Partido Liberal en 1941, el exilio acecha y los desbordes también. No sólo el calor agobia, sino la sensación de inseguridad, la delación. Areguá se convierte en el refugio de familias acomodadas, confinadas por las malas rachas de la fortuna. O al confinamiento político causado por el gobierno de turno. Para muchos, la política se vuelve una suerte de acomodo. "Los eternos herederos de la debilidad», dice el padre Esquivel, también involucrado en conspiraciones que tendieran a producir cambios sociales y económicos. Cambia la trama, pero los personajes tipo permanecen. El cura, como una de las autoridades del pueblo. El atropello sexual de los patrones a las domésticas. Se intuye, se cavila, se sospecha sobre sombras con aspecto de hombres y de nombres que no son dados en herencia porque los amores eran de paso. Los hijos bastardos, bastante numerosos, quedan a merced del recuerdo futuro que los absolverá.
Florino Villalba, activista político de la oposición, vive con revólver en la cintura noche y día y miedo de acabar baleado por los "guiones rojos», bandas de adictos a ultranza del Partido Colorado surgidos con la revolución de 1947. Débil y temeroso, abandona la empresa de Octavio, su hermano, de «volar el Palacio de Gobierno con toda la basura adentro», como dice, por lo que la acción no logra concretarse. Al sumarse otros al intento, éste fracasa, sale a la luz y el comisario del pueblo, Filomeno Maldonado, junto con los guiones rojos locales, asesina a Octavio. El deseo de cambio está siempre presente en el espíritu paraguayo, constituyendo una seguidilla de atentados, asaltos y asesinatos que nunca se aclaran.

Indalecio Rolón, el médico psiquiatra, también confinado por motivos políticos, hombre de gran cultura, maneja varios idiomas, sin por eso dejar de hablar un perfecto guaraní. El cambio de partido político, para él, es una forma de capear la situación indecorosa a la que había sido reducido. Termina siendo colorado. Nombrado director del Manicomio Nacional, cae en desgracia al ser acusado de violar a una interna de 14 años. Queda cesante, pero logra un puesto como médico rural en Areguá. Mantiene una relación con su vecina, Adelina Huertas, personaje que se vuelve a encontrar más tarde como protagonista principal de la novela Los Huertas. El deseo de ser trasladado a Asunción, le hace actuar irracional y rastreramente. Casimiro Huertas, hermano de Adelina, es un personaje conflictivo, lleno de aprensiones y angustias sobre las dudas que lo aquejan sobre si los dos hijos que tuvo su madre antes de casarse con Huertas fueron producto de la violación de que fue objeto por unos «cambás» de las tropas brasileras que ocuparon el Paraguay después de la guerra del '70. También lo perturba el no haber podido sacarle a su hermana Adelina el nombre del padre de Remigio, el hijo que ella tuvo. Acosado por sus perturbaciones, sostiene una situación de dependencia con su tía Gervasia, hermana de su padre, con quien habría mantenido relaciones. Casimiro Huertas, con todo, es un hombre virginal de alma que desea expiar sus pecados y los de los demás; idealiza la muerte y termina suicidándose. Sintetiza para Casaccia la idiosincracia del paraguayo en sus decepciones existenciales, en su deseo de cambiar una realidad que obra de Gabriel Casaccia SARA KARLIK 
lo involucra y consume. Todo su inconformismo lo concreta en la eliminación de sí mismo como salida decorosa.

Los herederos pareciera convertirse en un hito: el pasado que presenta ancestros que quizás destacaban por la no injerencia en el vicio, los herederos que no pudieron evitarlo y la sensación de esperanza de un porvenir en que el espíritu sano pudiera imponerse, como nudo temporal que circunscribe la existencia.

Tiempo-soledad-muerte es la trilogía que persigue a los protagonistas de Los Huertas, última novela de Casaccia publicada postumamente en 1981, un año después de su muerte. No tuvo, al igual que La Babosa en su momento, una crítica positiva.

Mario Pareda, abogado de empresas extranjeras, Filomeno Maldonado, el comisario de nueva aparición, Florino, el confinado político, y otros personajes, protagonizan esta novela. Florino y Adelina son amantes y protagonistas, desesperados por su mutua necesidad y por las odiosidades de las familias a las que pertenecen: los Villalba y los Huertas. Cuando Octavio es muerto por Filomeno Maldonado, Florino está a punto de caer en la redada. Rolón, que antecedió como amante a Florino, es quien le ayuda a escapar.

La novela se centra en Adelina Huertas, última heredera de la familia, en sus arrepentimientos y también obligaciones como heredera final, viviendo en un pasado con cargo a un presente de tedios y remordimientos y de apelación a las glorias anteriores. Florino resiente su condición de fracasado y vive con la ilusión de lo que pudo haber sido su destino si el coronel Evaristo Gavilán, en la revolución de 1947, no hubiese demorado el ataque a Asunción, postergando la orden que había recibido. De no haber ocurrido ese acontecimiento, su partido, el liberal, estaría en el gobierno y él en una posición de privilegio.

En Adelina Huertas perviven sus muertos y su espíritu es consolado por el alcohol. Se llega a hacer culto del linaje, de la virtud, de la tradición, en medio de rencillas que el tiempo no amansa y de recriminaciones continuas que tienden a delimitar posiciones sociales.

Remigio, el hijo oculto de Adelina Huertas, sale a la luz cuando se presenta con una orden judicial, mal habida, en la presunta casa de Casimiro Huertas, que ella ocupa, para reclamar la propiedad, el dinero y otras pertenencias, pues en el testamento de Casimiro aparece como hijo de éste. Todo se desmoronará de ahí en adelante para terminar con el suicidio de Adelina, mientras manipula el revólver que perteneció a Casimiro. Florino acaba mimetizado con los Huertas, en medio de la decadencia de las cosas.

Dos libros de cuentos le fueron publicados a $\mathrm{Ca}$ -

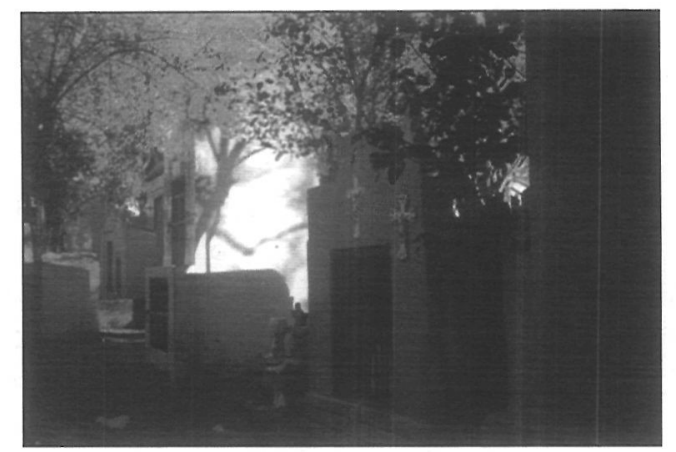

Cementerio de Areguá. (Foto: Mar Langa). saccia: «El guajhú» (1938) y El pozo (1947). En «El guajhú» (el aullido), que da el título a uno de sus libros, narra la historia de dos hermanos de madre, Tomás y Ceferino, de sus antagonismos. El perro aúlla por la muerte de su amo Ceferino, muerte que se atribuye a Tomás. La eterna lucha entre el bien y el mal, Caín y Abel, el hombre y su conciencia.

Otros cuentos de Casaccia, como «El Mayor», «Ciriaco», «La sortija», resaltan la indefensión del débil frente a la prepotencia del más fuerte, en tanto "La amberé» (la lagartija) $\mathrm{y}$ «La pora», lo vuelven a los mitos y leyendas que conforman su inquietud narrativa. La fatalidad y el destino conducen la trama de «El pozo». El autor maneja situaciones que resaltan frustraciones o delirios, haciendo del lenguaje preciso, insistente en el detalle, acucioso en el reborde con que remata el detalle, su característica definida. De pronto, también cede a la atracción del realismo mágico. La muerte es su aliada para fraguar el dramatismo de algunas situaciones. El sueño liberador es recurrente en sus cuentos. Otros cuentos aparecen entre 1925 y 1970. En «A ratos perdidos», los horrores de la Guerra del Chaco se manifiestan de forma velada, poéticamente, como evasión necesaria, búsqueda de lo que no se tiene a mano, que está en otra parte. «El hombre de las tres $\mathrm{A}$ » $\mathrm{y}$ «El sueño del revolucionario» se vinculan en la trama en la que gobiernistas y revolucionarios se confunden. El autor se adentra en la psicología torturada de los personajes, o en las pesadillas torturantes que los persiguen con la facilidad que supone la mimetización por la comunión de problemas. La asociación con el autor es irremediable.

Leer a Casaccia deja al lector, a menudo, a bout de souffle, traspirando ante la profusión de detalles y de información. Recurre a frases en guaraní para redondear el delineamiento

El puntillismo narrativo en la obra de Gabriel Casaccia SARA KARLIK 
que hace del paraguayo y transforman en el mejor transmisor de su mensaje.

Casaccia conoce lo que narra y tiene la habilidad de involucrarse y también hacerlo con el lector en los problemas que plantea, entiende el proceder de sus protagonistas, y les ayuda a delinear sus traumas con su omniscencia a menudo abrumante, puntillosa, extrema hasta el agotamiento. Saca a la luz las falencias y virtudes del hombre, que probablemente son las mismas que acosaban al autor. Casaccia diseña una época y transforma a los protagonistas asistidos por la realidad aplastante dentro de la existencia reducida por la imposibilidad de elección, característica que subraya su obra y la conforma como unidad. Sus personajes tienen un hilo común: van perdiendo talla para acabar derrotados, característica recurrente que quizás se convierte en su sello. El tiempo, en Areguá, se centra en los cambios de sus moradores, los que entrelazan las novelas de Casaccia y las unifica formando un todo.

Es innegable la influencia de Zola en la presentación de un naturalismo en el que los personajes van delineándose psicológicamente, sin perder detalle de sus caracterizaciones, utilizando el mismo puntillismo de sus descripciones narrativas.

En la narrativa de Casaccia generalmente se aprecia que el autor hace un balance de los males del hombre y su repercusión en el alma. De ahí su universalidad. Casaccia, como un Dostoievsky latinoamericano, los somete a una expurgación que acaba por reducirlos psicológicamente, tratando de mostrarlos en su desnudez. El mito recrea la remembranza y la idealización de personajes y momentos. Para Casaccia, Areguá es el universo infantil, la unidad que representa el todo paraguayo. 